\title{
Narratiewe tersydes in die vertelling van die Openbaring aan Johannes
}

\begin{abstract}
Author:
Jan A. du Rand ${ }^{1}$

Affiliation:

${ }^{1}$ Faculty of Theology,

North-West University,

Potchefstroom Campus,

South Africa

Corresponding author: Jan du Rand,

jdrth@yahoo.com

Dates:

Received: 03 June 2015

Accepted: 03 Dec. 2015

Published: 19 May 2016

How to cite this article:

Du Rand, J.A., 2016,

'Narratiewe tersydes in die vertelling van die Openbaring aan Johannes', In die Skriflig 50(3), a1995. http://dx.doi. org/10.4102/ids.v50i3.1995

\section{Copyright:}

(c) 2016. The Authors. Licensee: AOSIS. This work is licensed under the Creative Commons Attribution License.
\end{abstract}

Read online:

\begin{abstract}
Narrative asides in the narrative of the book of Revelation to John. Concerning the language (le parole) of the narrative of the book of Revelation, many ignorant and negative remarks have been thrown around. Therefore, to properly excavate the deadly accurate meaning of the narrative of the text requires narratological knowledge and skills from the informed linguist and exegete. Every hint of information to lighten up the text is very important. In the dramatic narrative of the book of Revelation we find most valuable references which have to be taken into consideration in analysing the text. They are called narrative asides, inter alia to awaken emotion in the reader, provide semantic explanations, give functional meaning to the sequence of the narrative or can just be causal. Combined with vocalisation these narrative aside enables the linguist and exegete hermeneutically to a better understanding of the message of Revelation and 4 Esra. The narrative of 4 Esra is chosen as a comparable and contemporary narrative to put the narrative of Revelation even more into narratological perspective.
\end{abstract}

\section{Navorsingsmatige vraagstelling en doel asook 'n definiering van wat' $n$ narratiewe tersyde is}

Wanneer'n vakkundige brontaalkenner en eksegeet ernstig by die uitleg van die boek Openbaring betrokke raak, kom die vraag by elke Nuwe-Testamentiese navorser op of daar buiten die taal, linguistiese, literêre, sosio-historiese agtergrond en teologiese perspektiewe nog enige ander bruikbare riglyne is wat die verstaan van 'n moeilike boek kan belig. In die hoogoond van eksegetiese en literére metodologie word die laai van literêre eksegetiese instrumentarium oopgeskuif om die rol van die relatief onbekende sogenaamde narratiewe tersydes af te stof en te benut. Dit is 'n legitieme vraag of die tersydes in die narratief van Openbaring hoegenaamd oor die literêre vermoeë beskik om die eksegese narratologies te verhelder, of is dit net weer 'n geval om ou bene met nuwe name in nuwe kiste oor te pak? Die eksegeet moet haarfyn luister na die narratiewe nuanses in die teks (vgl. Genette 1980; McKnight 1985; Porter \& Pitts 2013; RimmonKenan 1983). Dit is die aforistiese stelwyse van Johannes in Openbaring wat by wyse van spreke genoeg aanleiding gee om die legitieme vraag te vra of sy klinkende tersydes wel die gang van die verhaal enigsins beïnvloed.

Die huidige bydrae handel oor die doel van narratiewe tersydes in die verhaal van Openbaring en daarom moet narratiewe tersydes gedefinieer word. So 'n definiering is uiteraard vol knelpunte omdat narratiewe tersydes hulleself nie eksplisiet aanbied nie, maar slegs narratologies raakgesien en verstaan kan word. Dit is egter literêr gepas om by Openbaring as narratiewe literatuursoort die ploeg in te steek. As gevolg van die dramatiese en kenmerkende performatiewe taalgebruik (le parole) van Openbaring, kan dit ' $n$ dramatiese narratief genoem word (Du Rand 1990:8 e.v.; vgl. Scholes \& Kellogg 1966:67 e.v.). Die narratiewe verhaalstruktuur van Openbaring lewer 'n duidelike performatiewe kommunikasieproses (vgl. Wachter 1994:103) wat deeglik in ag geneem moet word. Daarvolgens word die leser retories betrek en moet ook retories daarop reageer. Die werklike eerste historiese lesers van Klein-Asië aan die einde van die eerste eeu n.C. kan eers die oordrag van betekenis sinvol ontvang wanneer elke leser ten volle probeer om die bedoelde leser te word, dié leser aan wie die outeur die narratief wil kommunikeer. Dit is juis hier waar tersydes as terloopse opmerkings of bydraende kommentaar ' $n$ bepaalde funksionele rol kan speel. Tesame met die dramatiese narratiewe styl, die opbou van argumentasie en die apokaliptiese karakter van die vertelteks, merk die eksegeet die tersyde narratologies aan en probeer om dit te ontleed om semanties sin van die geheel te maak. Die identifisering van die tersydes is alreeds 'n literêre kunsuiting.

Narratiewe tersydes as vertaling van die Engelse asides kan ook deur voetnote in die vertelteks vertaal word, of 'bedekte' of 'nie-regstreekse verwysings', 'syspraak', 'eenkant', en 'opsy', om die 
semantiese relevansie uit te druk (vgl. Van Belle 1985:47). ' $n$ Tersyde is in werklikheid ondefinieerbaar, want so gou as wat dit in ' $n$ definisie vasgepen word, is die narratiewe opwinding gedemp. Dit dien die doel om na die metanarratief van Openbaring as geheel te verwys en dit moet in die verwysingsraamwerk van Openbaring 1-22 beoordeel word. Die Christologiese metanarratief gee drakrag aan die narratief van Openbaring en mag nooit van die teks losgedink word nie. Die funksie van tersydes in ' $n$ narratief is om die verhaalgang van die narratief onderhoudend te beïnvloed. Die uiteindelike semantiese neerslag of boodskap word verkry deur die ko-teks (teksverband) en konteks (sosiohistoriese verbande) te bepaal en te ontleed. Die bekende eksegeet-taalkundige M.C. Tenney (1960) is, sover vasgestel kan word, die skepper van die term narrative asides. Hy beskou ... asides as showing something of the purpose of the author in communicating with his audience ... explaining places, names, occasions and situations so that the message might be unhindered (1960:364). Tenney (1960) gee ook die volgende definisie om narratiewe tersydes sinvol te verstaan en hulle narratiewe rol raak te sien:

Asides are sentences or paragraphs of explanatory comment, interjected into the running of the narrative of the story, and obviously intended to illumine some casual reference, or to explain how some important statements should be understood. (pp. 350-351)

Die narratiewe tersydes het beslis nie die funksie om uit hulle eie die dominante vertellyn te formuleer nie, maar om dit wel semanties funksioneel te beïnvloed. Hulle moet gedissiplineerd deur die narratologiese vakkundige raakgelees word en die toets van die onmiddellike en kotekstuele verbande van die narratiewe vloei van die verhaal slaag. Tersydes (asides) moet ook nie as interpolasies beskou word nie, maar is wesenlik deel van die teks (Poythress 1985:332; vgl. Riekert 2003:188 e.v.). Tersydes is ook al terloopse sinvolle tussenwerpsels genoem. Vir die narratologiese onkundige bly dit egter moeilik om die tersydes raak te sien en sinvol te interpreter. Tersydes vervul egter ' $n$ betekenisvolle rol om gekose narratiewe tekste soos 4 Esra en Openbaring se betekenis oop te breek en 'n semantiese bydrae te maak.

Die Belgiese Nuwe-Testamentikus Gilbert van Belle het 'n navorsingsmatige beskrywing van die Forschungsgeschichte van vergelykbare en verwante parallelle parenteses [tussenvoegings] in die Evangelie volgens Johannes gegee. Dit is nie dieselfde as narratiewe tersydes nie, maar kan as nou verwant daaraan beskou word (Van Belle 1985:208210). Van Belle identifiseer meer as 160 parenteses in die Johannesevangelie en verdeel die voorkomste in drie kategorieë, naamlik classification des parenthèses selon de contenu; classification grammaticale des parenthèses; et Les caractéristiques (1985:209-209; vgl. Hedrick 1986; O’Rourke 1979:211). Volgens Van Belle is die dominante doel van parenteses om die vertelling se kontinuïteit te verseker. Hy noem dit Beleitgedanken, Disgressions, Nebenbemerkungen, Nebengedanken en facon asydétique. Die teologiese kommentaar deur die parenteses en narratiewe tersydes gee kontinue drakrag aan die inhoud van die vertelteks. Van Belle se navorsing oor parenteses het direk tot hierdie verdere navorsing gelei om met in ag neming van die betekenis van parenteses verder deur verfyning die narratiewe tersydes te benoem. Dit dra ook daartoe by om die narratief tot 'n eenheid saam te bind. Ondersoeke in ander Evangelies, byvoorbeeld Markus (vgl. Hedrick 1986) en Lukas (Sheely 1992:17-19) het op Van Belle uitgebrei en soortgelyke resultate opgelewer.

In die vraag na die status questionis van die onderhawige onderwerp wat reeds hierbo genoem is, is dit uiters waardevol om ook van die bydrae deur Dal Lee in 2002 kennis te neem. Hy beskryf die narratiewe tersydes as parentetiese merkers deur die werklike outeur en die verteller van die teks (ibid:25-26). Dit kom dikwels voor waar die outeur van die verhaal gesaghebbend ingryp en die verteller se narratief sydelings onderbreek. In so 'n geval kan die narratiewe tersydes ook 'n lesertersyde genoem word. Die narratologiese verstaan van narratiewe tersydes is noodsaaklik en raak die leser direk. Die illokusionêre krag van die outeur se bedoeling en die perlokusionêre funksie deur die leser self funksioneer dus gesamentlik hand aan hand. Daarom is die narratiewe tersyde as kommentaar deur die werklike outeur, sowel as die leser se belangrike kennisname daarvan ewe belangrik uit 'n semantiese oogpunt gesien.

Die teorie en definiëring van narratiewe tersydes moet getoets word deur dit op voorbeelde van tipiese narratiewe tekste toe te pas. Die keuse het op die apokriewe vergelykbare en tydgenootlike geskrif 4 Esra geval. 4 Esra is tussen 70-100 n.C. waarskynlik na die val van Jerusalem geskryf. Die tydgenootlikheid daarvan met die Nuwe Testament maak daarvan 'n legitieme en interessante bron van vergelyking. 4 Esra is ' $n$ uiters vergelykbare narratief met Openbaring en bevestig die krag van narratiewe tekste gedurende die eerste eeu n.C.

\section{Narratiewe tersydes in die vergelykbare apokriewe 4 Esra as kontrolevoorbeeld}

Die narratief van 4 Esra is vergelykbaar met dié van Openbaring omdat albei verhale 'n kenmerkende dramatiese narratiewe opbou vertoon. In die geval van 4 Esra mond die plot uit in ' $n$ narratiewe klimaks wanneer Esra finaal van Uriël verneem dat God onteenseglik in beheer is al gaan dit ook tydelik sleg met die verbondsvolk terwyl hulle in ballingskap verkeer. Openbaring vertel van God se oordele, voorgestel as seëls, trompette en bakke, maar eindig in die Nuwe Jerusalem waar God en die Lam op die troon regeer (vgl. Du Rand 2014a:117; Himmelfarb 1983:67).

In die bestudering van 4 Esra (Esdrae liber 4 ) moet in gedagte gehou word dat ons slegs oor hoofstukke 3-14 beskik, omdat hoofstukke 1-2 en 14-15 nie aan die vertaling waaroor ons beskik, aangeheg is nie. 4 Esra het waarskynlik 
'n oorspronklike Semitiese onderbou gehad wat tot 'n Griekse vertaling aanleiding gegee het en uiteindelik by ons as 'n Latynse vertaalde teks uitgekom het. Dit is belangrik om die waarskynlike Semitiese onderbou semanties te verreken wanneer daar na narratiewe tersydes gesoek word. Hoofstukke 1-2 het later as 5 Esra bekend geraak en hoofstukke 14-15 as 6 Esra. Albei hierdie dele bestaan geheel en al op hulle eie, los van hoofstukke 3-14 (vgl. Charlesworth 1983; Klijn 1983; O’Donnell 2005; Stone 1990).

Hoofstukke 4-13 vertel op 'n boeiende wyse van die gesprekke tussen Esra en God. Die vertelde wêreld volgens die teks, speel in Babilon af na die val van Jerusalem in 587 v.C. (vgl. Stone 1990:46). Telkens wanneer Esra ernstig met God oor Israel praat wat so swaar in die ballingskap kry, antwoord Uriël namens God. Esra is ernstig en vra keer op keer: As God dan omgee vir sy eie, waarom ly sy volk so swaar in die ballingskap? Die outeur van 4 Esra worstel legitiem om die nood in God se huidige geskape wêreld te verstaan en om dit met sy geloof te laat rym. Dit word in die teologie die teodiseevraagstuk genoem, waar die klem op die mens se soeke na God se regverdigheid in omstandighede van swaarkry val. In hoofstukke 3-5 stort Esra sy hart passievol in gebed voor God uit, omdat hy meen die huidige situasie waarin sy volk hulle in ballingskap bevind, onregverdig is. Kyk 'n mens net na die Babiloniërs, gaan dit ontstellend goed met hulle! Die engel Uriël verduidelik telkens aan Esra dat hy nie God se weë op daardie stadium kan verstaan nie, maar dat hy dit wel later sal verstaan. Dit is die dialogise argumentasiepatroon tot aan die einde van hoofstuk 14. Esra smeek God passievol en word deur Uriël namens God geantwoord. In die laaste segment van die narratief het Esra se vrae opgedroog en lei die verteller die lesers om by God se ware bedoeling met sy volk se swaarkry uit te kom. Die klimaks breek aan as Esra die groter prentjie van God raaksien en God se wil aanvaar. Hy dra dit dan ook so aan die volk oor. Almal moet weet, God is en bly regverdig al verstaan die mens nie altyd God se weë nie (vgl. Du Rand 2014a).

In 4 Esra word 'n literêre narratiewe patroon van aaneenskakeling opgemerk. Die vloei van aaneengeskakelde argumentasie is logies en werk na 'n klimaks op. Die leser is op ' $n$ besondere manier deel van die narratief en word dus deelnemend meegevoer.

Veral die volgende tersydes word in 4 Esra aangetref:

- Redaksionele narratiewe tersydes: In 1:1-3 word die volgende redaksionele tersyde as redaksionele kommentaar vermeld:

Die tweede boek van die profeet Esra, die seun van Searia, hy was 'n gevangene in die land van die Meders, onder die regering van Artaxerxes, koning van die Perse.

Hierdie opmerking plaas die res van die vertelling in 'n gepaste historiese raamwerk met die oog op wat volg:

- Naamgewende tersydes: In 2:33b, $42 b$ en 3:1b word sydelings deur tersydes na die name van Esra en Salatiel verwys.
- Identifiserende tersydes: In 3:1c word Esra deur 'n sydelingse opmerking geïdentifiseer.

- Parentetiese tersydes: In 11:29 word terloops en sydelings na 'die een wat in die middel staan' verwys; en in 13:38b en 13:38d word na die 'versimbolisering deur die vuur of vlamme' verwys.

- Redegewende tersydes: In 15:26a staan: '... want die Here het geweet wie teen Hom oortree het'. Dit word gewoonlik ingelui deur want.

- Emotiewe tersydes: In 16:17 word gesê dat Esra emosioneel soos volg reageer: '... wee my, wie sal my in daardie bose dae oorlewer ...'.

- Tersydes van direkte adressering: In 16:35 e.v. word die lesers direk deur die werklike outeur aangespreek met die woorde:

Luister nou na hierdie dinge en verstaan dit, o dienaars van die Here. Aanskou die woord van die Here, ontvang dit en moenie die woorde van die Here met ongeloof begroet nie.

Die outeur van 4 Esra slaag meesterlik daarin om die leser sydelings deur narratiewe tersydes te bereik en te adviseer. Op so 'n wyse word die lesers nog beter in staat gestel om die apokaliptiese inhoud van die narratiewe argumentasie te verstaan. Die leser word dus psigologies en wesenlik diep geraak en deur die tersydes in 4 Esra begelei. Op so 'n wyse neem die tersydes 'n plek in die poëtiese stemming en ontvouing van die narratief in.

\section{Narratiewe tersydes dra by tot 'n dramatiese lees van die boek Openbaring}

Die dramatiese narratief van die boek Openbaring is hoofsaaklik ' $n$ eerstepersoonsnarratief. Dit is te verstane omdat die inhoud die karakter van gewaarmerkte getuienis volgens God se oordrag aan Christus, die engel en Johannes dra (vgl. Op 1:1-6). Daar is selfs op formele vlak nabootsende trekke met die mitologie te bespeur, beslis nie inhoudelik nie maar moontlik slegs formeel (vgl. Beale 1999:47-40; Lee 2002:91; Mounce 1998:76; Osborne 2003:104-109; Prigent 2001:81-84). Die eerstepersoonsvertellersperspektief beklemtoon ook die gesaghebbende historiese aard van die narratief deur Johannes. Sy getuienis kan en moet geglo word aangesien dit mense in 'n krisis in Klein-Asië moet dra. Die tersydes gee onder andere semantiese smering aan die narratief om dit glad te laat ontvou.

Die volgende kategorieë tersydes kom in die narratief van Openbaring voor en speel 'n rol in die semantiese funksie. Openbaring se narratiewe poëtiek is uniek, maar word met behulp van tersydes verstaanbaar aangebied. Die voorkoms van 'n narratiewe tersyde direk na 'n skielike verandering van werkwoordtyd is opvallend. Dit laat die navorser besef dat 'werkwoordtyd' nie in Grieks altyd aan tyd self gekoppel moet word nie, maar eerder op 'n proses of aspek van 'n saak dui (vgl. ook Aune 1997:1, 134; Du Rand 2012; Matthewson 2010:46-49). 
'n Seleksie van die ten minste 54 (vgl. Lee 2002:96) narratiewe tersydes vra intensiewer aandag. Die volgende seleksie tersydes illustreer die groeperings:

Redaksionele tersydes: Soos gebruiklik, stel die werklike outeur self die geskrif wat volg aan die leser in Openbaring 1:1-2 bekend. Dan kan die verteller maar oorneem, want die leser is ingelig. Dit is nie die Openbaring van Johannes nie, maar aan Johannes. In die volgende vers (v. 3), is daar 'n empatiese tersyde, naamlik 'Geseënd is die een wat dit voorlees, en ook hulle wat die woorde van die profesie hoor en wat daarin geskryf staan, nakom'. Dit skerp die leser op om onmiddellik aandag te skenk aan wat volg. Die daaropvolgende: '... want die bestemde tyd is naby' $(1: 3 b)$ is duidelik ' $n$ redegewend tersyde, ingelui deur die Griekse gar.

Die parentetiese tersydes in Openbaring 1:6 het die funksie om belangrike inligting deur te gee: '... wat ons 'n koninkryk gemaak het, priesters vir God, sy Vader ...'. Hierdie tersyde as parentese dra besliste eksegetiese betekenis wat verreken moet word. Dit is 'n narratiewe identifikasie om aan te dui wie die person is wat die volgende gaan kommunikeer. In 1:9d staan wel: '... op die eiland wat Patmos genoem word'. $\mathrm{Al}$ sou die leser dit waarskynlik geweet het, is dit steeds funksioneel om Johannes te identifiseer.

Wanneer die ster geïdentifiseer moet word, word dit deur 'n tersyde van identifisering gedoen: ' ... en die ster se naam is Bitterals ...' (Op 8:11a). Net so in 9:11a: '... in Hebreeus is sy naam Abaddon, en in Grieks Apollion'. Die nadere identifisering van 'die engel van die bodemlose put' kry baie meer trefkrag deur die bygevoegde narratiewe tersyde. Ook die prosessering van die narratief baat by die narratiewe tersyde. In Openbaring 9:12 staan byvoorbeeld: 'Die eerste ellende is verby; kyk, hierna kom daar nog twee!' (vgl. BSA 2014). Op so 'n wyse dien tersydes ook die strukturele opbou van die vertelling en maak dit die narratief nog interessanter (vgl. 11:14).

Die appèl-aan-die-leser-tersyde kom soms onverwags maar dringend na vore soos in Openbaring 13:9-10a: 'As iemand ore het, moet hy luister ...'. Dit geskied sonder die eksplisiete aankondiging van die spreker en is tipies van die outeur se tersydes. Die spreker kan óf ' $n$ hemelse wese, óf net die outeur-verteller wees. Verheldering is 'n belangrike sydelingse tegniek deur tersydes. In 14:4-5 staan: '... dit is die mense wat hulle nie met vroue besoedel het nie ...'. So 'n verheldering het die 144000 duidelik geïdentifiseer met 'n beeld uit die militêre wêreld. Eksegese kan hierna oorneem en die beeldspraak teologies interpreteer.

'n Belangrike narratiewe tersyde wat eksegeties veelseggend is, word in Openbaring 19:10b aangetref: '... want die getuienis van Jesus is die gees van die profesie'. Dit is die woorde van die engel of van die outeur-verteller wat die getuienis van Johannes definieer en sanksioneer. Daarom is dit 'n verduideliking as identiteitsaanduidende tersyde. Dieselfde opvoedkundige en verduidelikende funksie deur 'n tersyde is in 19:11c: '... en Hy oordeel met regverdigheid en Hy voer oorlog'. Na die tersyde in 20:2b wat suiwer inligting as ' $\mathrm{n}$ identifiserende tersyde bevat, deur die slang terloops te noem: '... die Duiwel en Satan', volg die veelseggende narratiewe tersyde wat eksegete deur die eeue diep laat dink het: 'Daarna moet hy vir 'n kort tydjie losgelaat word' (20:3b). Die 'loslating van Satan' aan die einde van die einde is 'n gewigtige eksegetiese en teologiese probleem.

Wanneer die leser tereg sou wou vra wie se name op die poorte gegraveer word, antwoord die werklike outeur deur 'n tersyde in 21:12b: '... die name van die twaalf stamme van die kinders van Israel'. Dit verskaf nie slegs inligting nie, maar is ook identiteitsaanduidend. Deur inligting en identiteit te voorsien, word die gang van die narratief sinvol bestuur. Net so sou 'n leser kon vra waarom daar nie 'n tempel in die hemel is nie. Dit is die belangrikste komponent in die godsdiens. Daarop antwoord die outeur-verteller in 21:22b met 'n narratiewe redegewende tersyde: 'want die Here God, die Almagtige, en die Lam is haar tempel'. Die belangrikheid van want-sinne (Grieks: gar) in die narratiewe redegewende tersydes moet nooit onderskat word nie.

Die laaste narratiewe tersyde bring die narratief tot 'n dramatiese en liturgiese einde. Deur die woorde: 'Hy wat hierdie dinge getuig, sê: "Ja, Ek kom gou"', het die reaksie van die outeur-verteller die leser tot die gebed aangespoor: 'Maranatha', met die narratiewe tersyde: 'Amen! Kom, Here Jesus!'

Samevattend kan gesê word dat die outeur deur narratiewe tersydes deurgaans by die leser se verstaansproses betrokke bly. Deur die emotiewe narratiewe tersydes word 'n appèl op die leser se emosie en wilskrag gerig, dikwels, eintlik meestel deur amen en geseënd as inleiding (vgl. 1:3a; 6c; 7b; 20:6; 22:7b, 14-15 en 20b). Kommentarierende narratiewe tersydes deur parenteses (vgl. 3: 8b; 20:5a), identifisering (vgl. 8:11a; 9:11b; $12: 9 b ; 16: 14 ; 20: 2 b ; 5 b ; 12 b ; 14 b$ ) en opheldering (vgl. 14:4-5; $19: 13 b ; 21: 17 c)$ kom algemeen in die narratief voor. Ook deur narratiewe dekodering van simbole word die leser ingelig gehou (vgl. 11:4; 19:8b; 20:8b).

Redegewende narratiewe tersydes word as kontekstuele narratiewe tersydes aangetref (vgl. 13:10b; 18a; 14:12; 16:1), en word meestaldeur gar ingelui.

\section{Gevolgtrekking: Is die kool die sous werd?}

Die narratiewe tersydes heg definitief semantiese waarde aan sowel die gang as die inhoud van die narratief van Openbaring toe. Die resultate is, semanties gesproke, nie epogmakend groot nie, maar narratologies funksioneel onontbeerlik. Tersydes is meestal implisiete kommentaar deur die werklike outeur wat die verteller in sy argumentasie onderbreek om 'n betekenisvolle tussenwerpsel te maak. Narratiewe tersydes beskryf die momente wanneer die werklike outeur op betekenisvolle wyse die literêre wêreld van die vertelling binnekom. 
Die ondersoek na die narratiewe tersydes het by wyse van gevolgtrekking ook die volgende twee verbandhoudende sake vir die eksegeet uitgelig: Die eerste is die belangrikheid van die Griekse werkwoord eidon en tweedens, die interessante rol van fokalisasie (vgl. Collins 1976:16; Du Rand 2006:565 e.v.; Uspensky 1973:82). Die werkwoord eidon ('ek het gesien') is dikwels in Openbaring aan narratiewe tersydes verbind. Dit kom algemeen by die eerste vier seëls in $6: 1,2,5,8,9$ voor asook in 8:2, 11a; $14: 6,12$; en 16:15 en 16b. Laasgenoemde geval volg op 16:13: '... ek het gesien (eidon) ...'

Deur fokalisasie bied die outeur sy ideologiese en fraseologiese (uitdrukkingswyse) perspektiewe aan deur ook van narratiewe tersydes gebruik te maak (vgl. Lee 2002:151; Smalley 2005:64-66; Uspensky 1973; Willett 1999:66). Die outeur-verteller fokus op wat hy sien terwyl die narratiewe tersydes die klem op die vertelling in die vertelling laat val. Op ideologiese terrein word die getuienis van Jesus geïdentifiseer met 'die gees van profesie' (19:10b). Op psigologiese vlak word die gesigspunt van waaruit die verteller handel deur die derdepersoonsnarratiewe tersydes aangedui. In 21:25b word gesê: ' ... en daar sal nie meer nag wees nie', terwyl dit met 'n gar (want) as narratiewe tersyde in 21:23b beantwoord word: '... want die heerlikheid van God het haar verlig en die Lam is haar lamp.'

Die semantiese funksie van want (gar) is onder andere om die intieme verhouding tussen die outeur-verteller en die leser te beklemtoon. Die outeur-verteller deel sy kennis met die leser wat nie self daaroor beskik nie. Op so 'n wyse bly die leser nie net ingelig nie, maar ook intiem betrokke. Die leser se verwagtings bly lewendig en hy word geensins deur die geïmpliseerde outeur of verteller geïntimideer nie.

Deur die navorsing is dus vasgestel dat die leser van Openbaring deur narratiewe tersydes boeiend by die dramatiese narratief betrokke gebly het.

\section{Erkenning \\ Mededingende belange}

Die outeur verklaar dat hy geen finansiële of persoonlike verbintenis het met enige party wat hom nadelig of voordelig kon beïnvloed het in die skryf van hierdie artikel nie.

\section{Literatuurverwysings}

Aune, D., 1997, Revelation, Vol. 1., Word Books, Dallas, TX.

Beale, G.K., 1999, The book of Revelation, Eerdmans, Grand Rapids, MI.

BSA, kyk Bybelgenootskap van Suid-Afrika
Bybelgenootskap van Suid-Afrika, 2014, Nuwe Testament en Psalms: 'n Direkte vertaling, BSA, Kaapstad.

Charlesworth, J.H., 1983, The Old Testament pseudepigrapha: Apocalyptic literature and testaments, Doubleday, Garden City, NY.

Collins, Y.A., 1976, The combat myth in the book of Revelation, Scholars Press, Missoula, MT.

Du Rand, J.A., 1990, Johannese perspektiewe: Inleiding tot die johannese geskrifte, Halfway House, Orion.

Du Rand, J.A., 2006, 'The ethical response of an alternative community in a critical situation: Marturia and martyrdom in the apocalypse of John', in J.G. van der Watt (ed.), Identity, ethics and ethos in the New Testament, pp. 565-596, De Gruyter, Berlin.

Du Rand, J.A., 2012, 'Die Openbaring aan Johannes', in J.G. van der Watt, H. du Toit, \& J. Barkhuizen (reds.), Die Grieks-Afrikaanse interliniêre Bybel, Christelike Uitgewersmaatskappy, Vereeniging.

Du Rand, J.A., 2014a, 'Die Openbaring aan Johannes', in Afrikaanse Standaard Vertaling (ASV), Christelike Uitgewersmaatskappy, Vereeniging.

Du Rand, J.A., 2014b, 'To adore God's identity through theodicy: Reading Revelation 6:9-11 in theological coherence with a remarkable classical example, 4 Ezra', in R.A. Eklund \& J.E. Phelan (eds.), Doing theology for the church: Essays in honor of Klyne Snodgrass, pp. 111-124, Wipf \& Stock, Eugene, OR.

Genette, G., 1980, Narrative discourse: An essay in method, transl. J.E. Lewin, Cornel University Press, New York.

Hedrick, C.W., 1986, 'Narrator and story in the Gospel of Mark: Hermeneia and paradosis', Unpublished seminar paper, Central States of the SBL.

Himmelfarb, M., 1983, Tours of hell: An apocalyptic form in Jewish and Christian literature, Fortress, Philadelphia, PA.

Klijn, A.F.J., 1983, Der lateinische Text der Apocalypse des Esra, Akademie, Berlin.

Lee, D., 2002, The narrative asides in the book of Revelation, University Press of America, Lanham, MD.

Matthewson, D.L., 2010, Verbal aspect in the book of Revelation: The function of Greek verb tenses in John's apocalypse, Brill, Leiden.

McKnight, E.V., 1985, The Bible and the reader: An introduction to literary criticism, Fortress, Philadelphia, PA.

Mounce, R.H., 1998, The book of Revelation, rev. edn., Eerdmans, Grand Rapids, MI.

O'Donnell, M.B., 2005, Corpus linguistics and the Greek of the New Testament, Sheffield Phoenix Press, Sheffield.

O'Rourke, J.J., 1979, 'Asides in the Gospel of John', Novum Testamentum 21(2), 210-219.

Osborne, G.R., 2003, Revelation, Baker Academic, Grand Rapids, MI.

Porter, S.E. \& Pitts, A.W. (eds.), 2013, The language of the New Testament, Brill, Leiden.

Poythress, V.S., 1985, 'Johannine authorship and the use of intersentence conjunctions in the book of Revelation', Westminster Theological Journal 47(2), 329-336.

Prigent, P., 2001, Commentary on the apocalypse of St John, Mohr, Tübingen.

Riekert, S.J.P.K., 2003, 'Grammatical case in the text of Revelation 4 and 5', Acta Theologica 26(2), 329-336.

Rimmon-Kenan, G., 1983, Narrative fiction: Contemporary poetics, Methuen, London.

Scholes, R. \& Kellogg, R., 1966, The nature of narrative, Oxford University Press, Oxford.

Sheely, S.M., 1992, Narrative asides in Luke-Acts, JSNT Supplement Series 72, Journal for the Study of the Old Testament Press, Sheffield.

Smalley, S.S., 2005, The Revelation to John, SPCK, London.

Stone, M.E., 1990, Fourth Ezra: A commentary on the book of fourth Ezra, Fortress, Minneapolis, MN

Tenney, M.C., 1960, 'The footnotes of John's Gospel', Bibliotheca Sacra 117(3), 350-364.

Uspensky, B., 1973, A poetics of composition: The structure of the artistic text and typolology of a compositional form, transl. V. Zavarin \& S. Wittig, University of California Press, Berkeley, CA.

Van Belle, G., 1985, Les parenthèses dans L'evangile de Jean: Aperçu historique et classification, Peeters, Leuven.

Wachter, S.L., 1994, 'An analysis of the literary structure of the book of Revelation according to textlinguistic methods', PhD dissertation, Baptist Theological Seminary, Louisville, KY.

Willett, T.W., 1999, Eschatology in the theodicees of 2 Baruch and 4 Ezra, JSOT Press, Sheffield. 